\title{
Evaluation of the Distribution and Factors Affecting Blood Pressure Using Medical Checkup Data in Japan
}

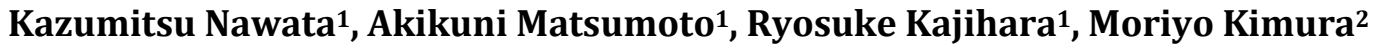 \\ ${ }^{1}$ Graduate School of Engineering, University of Tokyo, Tokyo, Japan \\ ${ }^{2}$ The Public Health Institute, Tokyo, Japan \\ Email: nawata@tmi.t.u-tokyo.ac.jp,matsumoto@tmi.t.u-tokyo.ac.jp,r.kajihara7@gmail.com,kimuramoriyo@gmail.com
}

How to cite this paper: Nawata, K., Matsumoto, A., Kajihara, R. and Kimura, M. (2017) Evaluation of the Distribution and Factors Affecting Blood Pressure Using Medical Checkup Data in Japan. Health, 9, 124137.

http://dx.doi.org/10.4236/health.2017.91009

Received: December 30, 2016

Accepted: January 17, 2017

Published: January 20, 2017

Copyright ( 2017 by authors and Scientific Research Publishing Inc. This work is licensed under the Creative Commons Attribution International License (CC BY 4.0).

http://creativecommons.org/licenses/by/4.0/

\begin{abstract}
In this paper, we first evaluated the distribution of blood pressure (BP) using a dataset containing 113,979 measurements in 48,022 individuals with the cooperation of one health insurance society in Japan from April, 2013 to March, 2016. The means of the systolic BP (SBP) and diastolic BP (DBP) were 125.4 and $77.6 \mathrm{mmHg}$ with standard deviations of 16.5 and $11.7 \mathrm{mmHg}$, respectively. Under the $140 / 90$ criterion, $21.6 \%$ of the measurements showed hypertension. According to the World Health Organization/International Society of Hypertension criterion, $16.4 \%, 4.2 \%$ and $0.96 \%$ were classified as grades 1,2 and 3, respectively. The factors affecting BP were evaluated by a regression analysis and were found to include age, gender, some eating habits, daily activities, smoking, drinking alcohol, sleeping and wages. Age was a very important factor, and the age cohorts from the previous study might be revised based on these findings. Among factors that individuals can control, the influence of drinking alcohol is very large. Comparing to an individual who does not drink, SBP and DBP of a heavy drinker are more than $5.0 \mathrm{mmHg}$ higher on the average.
\end{abstract}

\section{Keywords}

Blood Pressure, Hypertension, Distributions of SBP and DBP, Health Checkups, Factors Affecting BP

\section{Introduction}

Blood pressure (BP) is considered to be one of the most important health factors. The World Health Organization (WHO) [1] states "Worldwide, raised blood pressure is estimated to cause 7.5 million deaths, about $12.8 \%$ of the total of all 
deaths. This accounts for 57 million disability adjusted life years (DALYS) or $3.7 \%$ of total DALYS. Raised blood pressure is a major risk factor for coronary heart disease and ischemic as well as hemorrhagic stroke." If the systolic BP (SBP, the BP when the heart beats while pumping blood) $\geq 140 \mathrm{mmHg}$ or the diastolic BP (DBP, the BP when the heart is at rest between beats) $\geq 90 \mathrm{mmHg}$ (hereafter, 140/90), a person is classified as having high (raised) BP or hypertension [2]. (Although manual office BP is usually used, automated office BP [3] or ambulatory BP [4] measurements have recently been recommended to avoid measurement errors [5] and white-coat effects. The recommended threshold values of hypertension when measured by these measurement methods are lower than 140/90.) Hypertension is now a problem worldwide [6] [7], including in developing countries [8] [9] [10]. WHO [1] estimated that about $40 \%$ of the world population aged 25 or over exhibited hypertension and that the number of people with uncontrolled hypertension rose from 600 million in 1980 to nearly 1 billion in 2008. Hypertension is frequently associated with hypertensive heart disease [11]. It was estimated that 50 million or more Americans had hypertension requiring treatment [12] [13]. Chaobanian et al. [12] pointed out that awareness of hypertension improved from $51 \%$ in $1976-1980$ to $70 \%$ in 1999 2000 . The percentage of patients receiving treatment increased from $31 \%$ to $59 \%$, and the percentage of individuals with BP below 140/90 increased from $10 \%$ to $34 \%$ in the same periods. The median SBP of Americans aged 60-74 declined by $16 \mathrm{mmHg}$ from 1960 to 1991, and the age-adjusted death rates from stroke and coronary heart disease declined by $50 \%$ and $60 \%$ since 1972 , respectively. They concluded that "These benefits occurred independent of gender, age, race or social status."

The National Heart, Lung and Blood Institute [13] [14] classified hypertension as stage 1 if SBP is $140-159 \mathrm{mmHg}$ or DBP is $90-99 \mathrm{mmHg}$ and stage 2 if $\mathrm{SBP} \geq 160 \mathrm{mmHg}$ or DBP $\geq 100 \mathrm{mmHg}$. The risk of heart disease increases as BP increases for individuals of all ages [15] [16]. WHO and the International Society of Hypertension (ISH) [17] gave guidelines for managing hypertension from epidemiological studies and from clinical trials. WHO-ISH described the risk of cardiovascular disease (CVD), the factors affecting BP, and the effects of treatments. Hypertension is classified into three categories: grade 1 (middle hypertension), defined as SBP of 140 - $159 \mathrm{mmHg}$ or DBP of 90 - $99 \mathrm{mmHg}$; grade 2 (moderate hypertension), defined as SBP of 160 - $179 \mathrm{mmHg}$ or DBP of 100 $109 \mathrm{mmHg}$; and grade 3 (severe hypertension) defined as SBP $\geq 180 \mathrm{mmHg}$ or DBP $\geq 110 \mathrm{mmHg}$. Based on the hypertension grade, other risk factors, target-organ damage and associated clinical conditions, patients are classified into low-, medium-, high- and very-high-risk groups. The risk of a major cardiovascular events in the following 10 years is about $20 \%-30 \%$ and $30 \%$ or over in the high-risk and very-high-risk groups, respectively. In Japan, the medical expenditure for hypertension and related disease was 1.85 trillion yen, which accounted for $4.5 \%$ of total medical expenditures (40.8 trillion yen) in fiscal year 2014 [18]. Moreover, comorbid hypertension increases the medical expenditures of pa- 
tients with other diseases such as diabetes [19]. Hypertension also reduces happiness and life satisfaction [20] [21]. Therefore, the true medical cost of hypertension might be much higher than the direct cost alone. To evaluate the effects of BP on societies, it is necessary to know the distribution of BP in the population, including normal and healthy individuals. However, it is very difficult and costly to obtain a large-scale individual dataset that includes many normal and healthy individuals because such people do not usually go to hospitals or clinics voluntarily.

Therefore, special surveys are necessary, but the number of participants is limited in most studies. Joffres et al. [22] analyzed the BP in Canada and the United States using the Third National Health and Nutrition Survey (NHANES III) and the Canadian Heart Health Survey (CHHS). The numbers of available BP measurements were 23,111 and 15,326 in Canada and the United States, respectively. They found that mean BP showed similar trends by age, with the hypertension prevalence for individuals in the same age range (18 - 74) being $20.1 \%$ and $21.1 \%$ as determined by NHANES III and CHHS, respectively. About a half of diabetes patients had hypertension with very poor control in both countries. Rose [23] pointed out that there were large differences between the distributions of SBP among Kenyan nomads and London civil servants, with the levels of the former much lower than the levels of the latter. It has also been suggested that race, genetic and environmental factors, and health administrative and practice patterns are important determinants of BP [4] [10] [24]. Therefore, it is necessary to evaluate the BP data by country.

In Japan, the NIPPON DATA 2010 survey [25], financed by a grant from the Ministry of Health, Welfare, and Labor, was conducted in 2010. In this survey, the BP levels of 2891 participants were observed. The averages of SBP were 137.4 and $130.8 \mathrm{mmHg}$ for males and females, respectively. Based on the national surveys, there were decreasing 50-year trends in SBP in all ages and genders. Similar decreasing trends were observed in DBP in females; however, there was no clear trends in DBP in males [26]. Fujiyoshi et al. [27] studied the relation between CVD and BP using the data of 68,309 individuals grouped into cohorts by age and gender. They observed 1944 CVD death over 10.2 years. They concluded that there was a positive relation between CVD and BP in all cohorts.

In Japan, most workers 40 or older are required to have medical checkups once a year independent of their health conditions by the Industrial Safety and Health Act [28]. (To our knowledge, Japan is the only country that has such a system among major countries and it is extremely costly to do such a survey in other countries.) Private companies and central and local governments form health insurance societies for their employees in Japan. According to the National Federation of Health Insurance Societies [29], made up of societies formed by private companies, the number of members (employees and their family members satisfying certain conditions) of such societies is 30 million. This means that datasets for a huge number of normal individuals, much bigger than any datasets ever used before, already exist, and no additional cost or effort 
is necessary to develop them. Moreover, the health insurance societies pay the medical expenditures of their members and obtain all of their medical information, including their medical conditions, treatments, institutions used, and amounts paid for medical care. Therefore, if their health and medical information is used properly, it can aid in the improvement and effective use of health and medical resources. However, as of the present, this information has never been used for this purpose. The health insurance societies are required to keep their data for five years by law, but most of the important and useful data are discarded after that.

We have succeeded in obtaining the cooperation of one health insurance society. This study is the first study that uses the health and medical information stored by a health insurance society. The BP levels of a Japanese population are analyzed using a dataset containing 113,979 measurements in 48,022 individuals. First, the BP distribution is evaluated, and then the factors that might affect BP are analyzed in a regression analysis.

\section{Data and Distribution of BP}

The dataset used in this study was obtained with the cooperation of the health insurance society of one large Japanese corporation that has offices and operational centers throughout Japan. The basic characteristics and various results of health and medical checkups, including BP measurements, of all employees (including normal healthy ones) and their family members (voluntary) of the cooperation are available. For the employees, their standard wages (average monthly wages between April and June) are also available. The sample period is from April, 2013 to March, 2016. The results of 113,979 medical checkups of 48,022 individuals are used in this study. Totals of 29,749, 8459 and 10,814 individuals had checkups three, two and one time, respectively. The ages of the individuals in the dataset ranged from 39 (including some individuals who turned 40 within that fiscal year) to 74 years. Figure 1 and Figure 2 show the distributions of SBP and DBP. Excluding measurements that were too low (less than 10 $\mathrm{mmHg}$ ) or too high (over 300 ), a summary of 113,967 measurements is given in

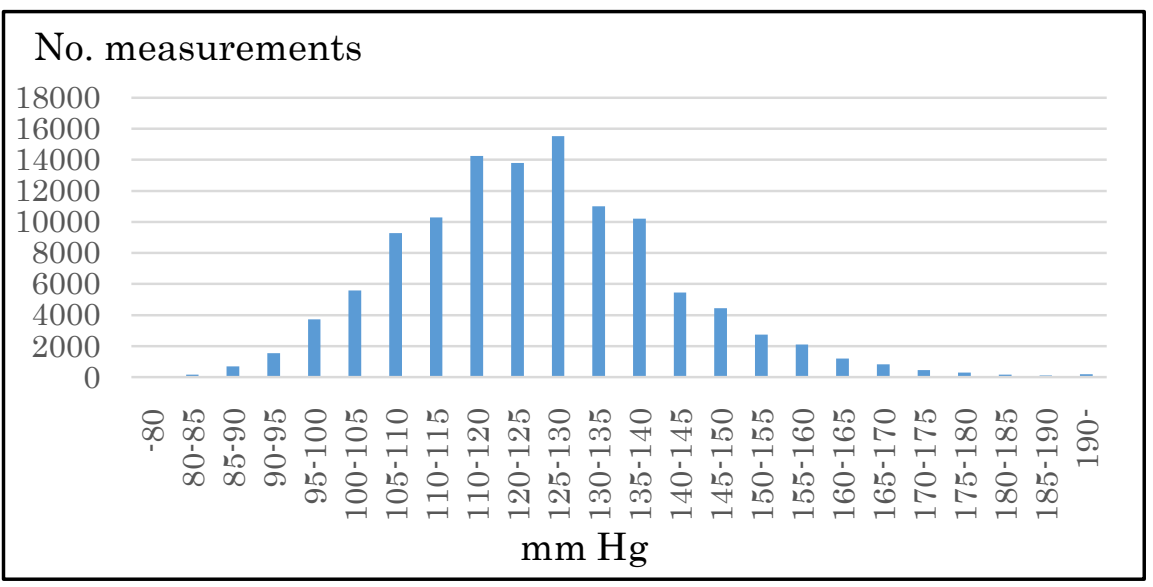

Figure 1. Distribution of systolic blood pressure (SBP). 


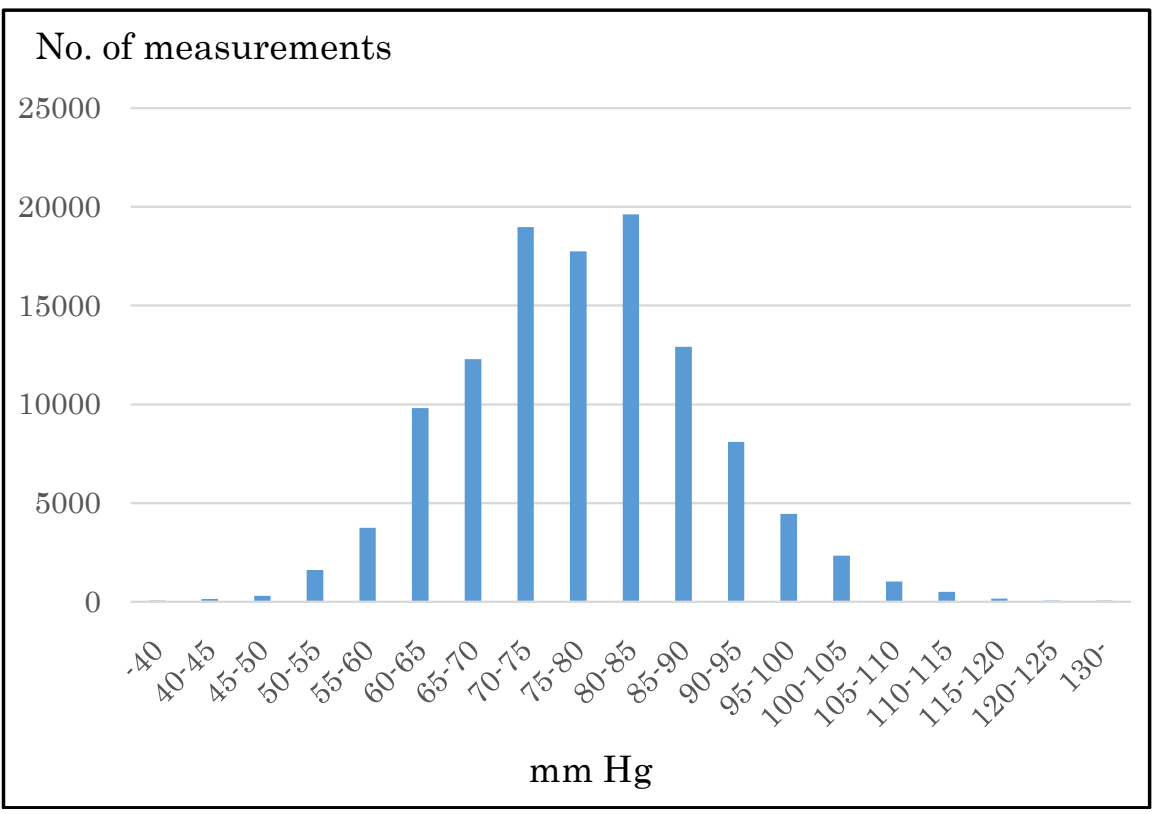

Figure 2. Distribution of systolic blood pressure (DBP).

Table 1. The means were 125.4 and $77.5 \mathrm{mmHg}$ with standard deviations (SD) of 16.5 and $11.7 \mathrm{mmHg}$ for SBP and DBP for all observations. The global mean SBP (age 18 or over) according to WHO [30] was 124.5 in 2010 and 124.6 $\mathrm{mmHg}$ in 2014. Our results are very close to these numbers. For males, the mean SBP and DBP levels were 127.2 and $79.0 \mathrm{mmHg}$ with SD of 15.7 and 11.3 $\mathrm{mmHg}$, respectively. For females, the mean SBP and DBP levels were 119.0 and $72.0 \mathrm{mmHg}$ with SD of 17.5 and $11.8 \mathrm{mmHg}$, respectively. The BP of males was higher than that of females.

Figure 3 shows the relation between SBP and DBP. There exists a positive correlation between these two variables, as expected (the correlation coefficient was 0.785 ), and $21.6 \%$ of the measurements show hypertension. This figure is also close to the WHO estimate [30] that $22.3 \%$ of the world population aged 18 or over exhibited hypertension in 2014. Among these $21.6 \%$ of measurements showing hypertension in the present study, 10.2\% had both SBP and DBP over the $140 / 90$ threshold value, $6.9 \%$ were isolated systolic hypertension cases where SBP $140 \mathrm{mmHg}$ but DBP $<90 \mathrm{mmHg}$, and $4.4 \%$ were isolated diastolic hypertension cases where DBP $\geq 90 \mathrm{mmHg}$ but SBP $<140 \mathrm{mmHg}$. According to the WHO-ISH criteria, $16.4 \%, 4.2 \%$ and $0.96 \%$ were classified as grades 1,2 and 3 , respectively.

\section{Regression Analysis of Variables Affecting BP}

In this section, we evaluate the factors that might affect BP. As already mentioned, age, gender and racial/ethnic background are important basic characteristics of individuals. The time trend is another important factor. In terms of racial/ethnic background, Japan is a homogenous society and it is not necessary (and not possible) to evaluate its effects. The other variables that might affect BP 
Table 1. Summary of SBP and DBP.

\begin{tabular}{ccccccc}
\hline & \multicolumn{2}{c}{ All } & \multicolumn{2}{c}{ Male } & \multicolumn{2}{c}{ Female } \\
\cline { 2 - 7 } & SBP & DBP & SBP & DBP & SBP & DBP \\
\hline Mean & 125.4 & 77.5 & 127.2 & 79.0 & 119.0 & 72.5 \\
Median & 124.0 & 77.5 & 126.0 & 79.0 & 118.0 & 72.0 \\
Maximum & 246.0 & 172.0 & 246.0 & 172.0 & 227.0 & 146.0 \\
Minimum & 67.0 & 29.0 & 67.0 & 35.0 & 71.0 & 29.0 \\
SD & 16.5 & 11.7 & 15.7 & 11.3 & 17.5 & 11.8 \\
No. of measurements & \multicolumn{2}{c}{113,967} & \multicolumn{2}{c}{88,575} & \multicolumn{2}{c}{25,392} \\
\hline
\end{tabular}

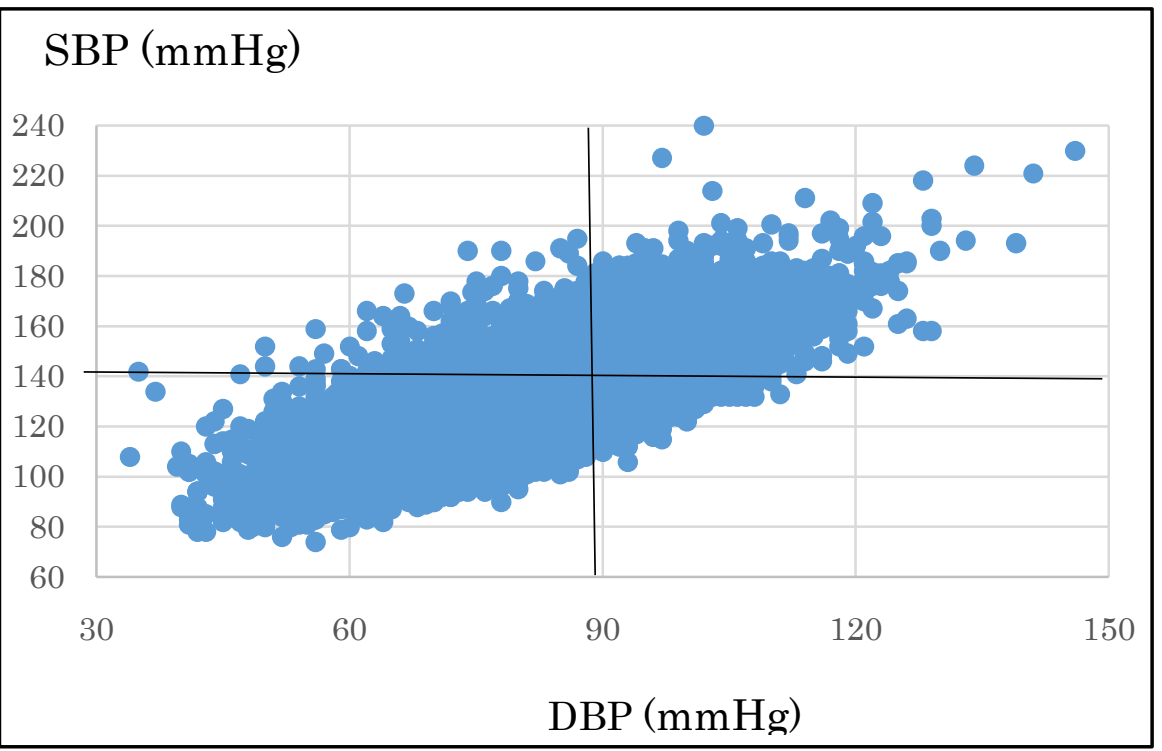

Figure 3. Relation of SBP and DBP.

are weight, obesity, exercise, eating habits, alcohol consumption, stress, educational level, and time [12] [31]-[36]. Our dataset contained most of these factors. Regression models were used in the analysis.

\subsection{Analysis of SBP}

First, we considered a simple model to evaluate the gross effects of age and gender (Model 1A):

$$
\mathrm{SBP}_{i}=\beta_{1}+\beta_{2} \text { Age }+\beta_{3} \text { Female }+u_{i},
$$

where $u_{i}$ is an error term. The mean and SD of Age were 49.7 and 7.2 years, respectively. This model gives basic information of age and gender that may be helpful for cohort studies. Female (male: 0, female: 1) was used for gender; $22.2 \%$ of the measurements was obtained from female. The results of the estimation are given under "Model 1A" in Table 2. The estimate of Age was 0.518 and its t-value was 79.97, which implies that $A g e$ is a very important variable. The average SBP of an individual aged 65 years was $13.0 \mathrm{mmHg}$ higher than that an individual aged 40 years. The estimate for Female was -8.16 , and there was a 
Table 2. Results of estimation: SBP equations.

\begin{tabular}{|c|c|c|c|c|c|c|c|c|c|}
\hline \multirow[b]{2}{*}{ Variable } & \multicolumn{3}{|c|}{ Model 1A } & \multicolumn{3}{|c|}{ Model 1B } & \multicolumn{3}{|c|}{ Model 1C } \\
\hline & Estimate & S. E. & $t$-value & Estimate & S. E. & $t$-value & Estimate & S. E. & $t$-value \\
\hline Constant & 101.483 & 0.326 & 311.041 & 70.819 & 0.522 & 135.736 & 68.169 & 1.838 & $37.098^{*}$ \\
\hline Age & 0.518 & 0.006 & $79.966^{*}$ & 0.495 & 0.007 & $69.655^{*}$ & 0.420 & 0.008 & $52.266^{*}$ \\
\hline Female & -8.158 & 0.112 & $-72.968^{\star}$ & -3.835 & 0.134 & $-28.700^{*}$ & -3.596 & 0.213 & $-16.876^{\star}$ \\
\hline Hight & & & & 0.072 & 0.092 & 0.789 & 0.072 & 0.009 & $7.965^{\star}$ \\
\hline BMI & & & & 1.149 & 0.013 & $89.081^{\star}$ & 1.253 & 0.014 & $87.640^{*}$ \\
\hline Anamnesis & & & & 1.369 & 0.099 & $13.864^{\star}$ & 1.356 & 0.104 & $13.024^{*}$ \\
\hline Eat_fast & & & & -0.169 & 0.108 & -1.566 & -0.142 & 0.112 & -1.264 \\
\hline Late_Supper & & & & -0.082 & 0.105 & -0.779 & 0.039 & 0.107 & 0.365 \\
\hline After_Supper & & & & -0.708 & 0.145 & $-4.882^{\star}$ & -0.857 & 0.156 & $-5.478^{\star}$ \\
\hline No_Breakfas & & & & 0.927 & 0.119 & $7.818^{*}$ & 0.842 & 0.120 & $7.032^{*}$ \\
\hline Exercise & & & & 0.004 & 0.133 & 0.032 & -0.003 & 0.141 & -0.025 \\
\hline Daily_activity & & & & -0.383 & 0.115 & $-3.327^{\star}$ & -0.737 & 0.125 & $-5.899^{*}$ \\
\hline Walk_fast & & & & 0.010 & 0.102 & 0.096 & 0.160 & 0.108 & 1.488 \\
\hline Smoke & & & & -0.436 & 0.107 & $-4.089^{\star}$ & -0.748 & 0.107 & $-6.971^{\star}$ \\
\hline Alcofol_freq & & & & 1.711 & 0.089 & $19.185^{*}$ & 1.852 & 0.091 & $20.284^{*}$ \\
\hline Alcohol_amount & & & & 0.406 & 0.066 & $6.142^{*}$ & 0.558 & 0.067 & $8.349^{*}$ \\
\hline Sleep & & & & 0.862 & 0.102 & $8.462^{\star}$ & 0.943 & 0.107 & $8.820^{*}$ \\
\hline Trend & & & & -0.091 & 0.057 & -1.601 & -0.048 & 0.061 & -0.777 \\
\hline Wage & & & & & & & -0.130 & 0.004 & $-30.843^{\star}$ \\
\hline $\mathrm{R}^{2}$ & & 0.094 & & & 0.1704 & & & 0.1628 & \\
\hline $\begin{array}{c}\text { No. of } \\
\text { measurements }\end{array}$ & & 113,967 & & & 95,364 & & & 82,735 & \\
\hline & & 15.706 & & & 14.599 & & & 14.911 & \\
\hline
\end{tabular}

SE: Standard Error. ${ }^{*}$ significant at the $1 \%$ level.

significant difference between males and females.

Next, we considered two models that included several variables that might affect BP, Model 1B and Model 1C. Model 1B is as follows:

$$
\begin{aligned}
\mathrm{SBP}_{i}= & \beta_{1}+\beta_{2} \text { Female }+\beta_{3} \text { Height }+\beta_{4} \text { BMI }+\beta_{5} \text { Anamnesis }+\beta_{6} \text { Eat_fast } \\
& +\beta_{7} \text { Late_Supper }+\beta_{8} \text { After_Supper }+\beta_{9} \text { No__Breakfast } \\
& +\beta_{10} \text { Exercise }+\beta_{11} \text { Daily_activity }+\beta_{12} \text { Walk_fast }+\beta_{13} \text { Smoke } \\
& +\beta_{14} \text { Alcofol_freq }+\beta_{15} \text { Alcohol_amount }+\beta_{16} \text { Sleep }+\beta_{17} \text { Trend }+u_{i} .
\end{aligned}
$$

The explanatory variables used were as follows: Height $(\mathrm{m}), B M I$ (body mass index), Anamnesis (1: with anamnesis; 0: otherwise), Eat_fast (1: eating faster than other people; 0: otherwise), Late_Supper (1: eating supper within two hours before bedtime three times or more in a week; 0: otherwise), After_supper (1: eating snacks after supper three times or more in a week, 0 : otherwise), $N o_{-}$ 
breakfast (1: not eating breakfast three times or more in a week; 0: otherwise), Excercise (1: doing exercise for 30 minutes or more twice or more in a week for more than a year; 0 otherwise), Daily_activity (1: doing physical activities (walking or equivalent) for one hour or more daily, 0: otherwise), Walk_fast (1: walking faster than other people of a similar age and the same gender; 0: otherwise), Smoke (1: smoking; 0: otherwise), Alcohol_freq (0: not drinking alcoholic drinks, 1: sometimes, 2: everyday), Alcohol_amount (0: not drinking; 1: drinking less than $180 \mathrm{ml}$ of Japanese sake wine (with an alcohol percentage of about 15\%) or equivalent alcohol in a day when drinking; 2: drinking 180 - $360 \mathrm{ml}$; 3: drinking 360 - $540 \mathrm{ml}$; 4: drinking $540 \mathrm{ml}$ or more), Sleep (1: sleeping well; 0: otherwise), and Trend, which is the time trend by year and given by (year of checkup-2013). This model gives useful information about effective treatment methods of hypertension.

A total of 95,364 measurements that had no missing values for any of the explanatory variables were used in this model. Height was another basic characteristic of individuals, with a mean of $1.675 \mathrm{~m}$ and SD of $0.53 \mathrm{~m}$; $B M I$ gave information about obesity with a mean of 23.7 and SD of 3.96; and Anamnesis represented the current health condition of the individual, with $47.9 \%$ of subjects giving an anamnesis. Eat_fast, Supper_time, After_supper and No_breakfast represented eating habits, and 31.8\%, 42.1\%, 13.3\% and 24.0\% answered 1 for these variables, respectively. Exercise, Daily_activity and Walk_fast represented exercise and physical abilities, and $18.1 \%, 28.3 \%$ and $40.1 \%$ answered "yes" for these variables. For Smoke, 38.7\% answered yes. Alcohol_freq and AIcohol_amount are variables regarding alcohol consumption; $35.0 \%, 27.3 \%$ and $37.6 \%$ answered 0, 1 and 2 for Alcohol_freq, and 35.0\%. 22.5\%, 28.1\%, 11.3\% and 3.3\% answered 0, 1, 2, 3 and 4 for Alcohol_amount, respectively. Sleep was used to evaluate stress, and $63.0 \%$ answered that they could sleep well. The results of the estimation are given under Model 1B in Table 2. The estimates of Age, Female, BMI, Anamnesis, No_Breakfast, Daily_activity, Smoke, Alcofol_freq, Alcohol_amount and Sleep were significant at the 1\% level, and these variables were considered to be important variables affecting SBP. Height, Eat_fast, Late_Supper, After_Supper, Walk_fast and Trend were not significant at the $5 \%$ level, and we could not confirm any effects of these variables.

Next, we considered Model 1C.

$$
\begin{aligned}
\mathrm{SBP}_{i}= & \beta_{1}+\beta_{2} \text { Female }+\beta_{3} \text { Height }+\beta_{4} \text { BMI }+\beta_{5} \text { Anamnesis }+\beta_{6} \text { Eat_fast } \\
& +\beta_{7} \text { Late_Supper }+\beta_{8} \text { After_Supper }+\beta_{9} \text { No__Breakfast }+\beta_{10} \text { Exercise } \\
& +\beta_{11} \text { Daily_activity }+\beta_{12} \text { Walk_fast }+\beta_{13} \text { Smoke }+\beta_{14} \text { Alcofol_freq } \\
& +\beta_{15} \text { Alcohol_amount }+\beta_{16} \text { Sleep }+\beta_{17} \text { Trend }+\beta_{18} \text { Wage }+u_{i} .
\end{aligned}
$$

This model contains Wage (average monthly wage from April to June), which represented the social and economic status of individuals and we can evaluate the effect of the social and economic status by this model. Since Wage was available only for workers, 82,735 observations of workers were used in the analysis. The average wage was 36.8 (10,000 yen) with SD of 13.8. The results of the estimation are given under Model $1 \mathrm{C}$ in Table 2. In the previous model, the 
estimates of Age, Female, BMI, Anamnesis, No_Breakfast, Daily_activity, Smoke, Alcofol_freq, Alcohol_amount, and Sleep became significant at the $1 \%$ level. In this model, Height and After_supper became significant at the $1 \%$ level. The estimate of Wage was -0.130 and its t-value was -30.843 ; it was an important variable affecting SBP.

\subsection{Analysis of DBP}

Next, DBP was analyzed by three models, as before. They were:

Model 2A,

$$
\mathrm{DBP}_{i}=\beta_{1}+\beta_{2} \text { Age }+\beta_{3} \text { Female }+u_{i} .
$$

Model 2B,

$$
\begin{aligned}
\mathrm{DBP}_{i}= & \beta_{1}+\beta_{2} \text { Female }+\beta_{3} \text { Height }+\beta_{4} \mathrm{BMI}+\beta_{5} \text { Anamnesis }+\beta_{6} \text { Eat_fast } \\
& +\beta_{7} \text { Late_Supper }+\beta_{8} \text { After_Supper }+\beta_{9} \text { No_Breakfast }+\beta_{10} \text { Exercise } \\
& +\beta_{11} \text { Daily_activity }+\beta_{12} \text { Walk_fast }+\beta_{13} \text { Smoke }+\beta_{14} \text { Alcofol_freq } \\
& +\beta_{15} \text { Alcohol_amount }+\beta_{16} \text { Sleep }+\beta_{17} \text { Trend }+u_{i} .
\end{aligned}
$$

Model 2C,

$$
\begin{aligned}
\mathrm{DBP}_{i}= & \beta_{1}+\beta_{2} \text { Female }+\beta_{3} \text { Height }+\beta_{4} \text { BMI }+\beta_{5} \text { Anamnesis }+\beta_{6} \text { Eat_fast } \\
& +\beta_{7} \text { Late_Supper }+\beta_{8} \text { After_Supper }+\beta_{9} \text { No_Breakfast }+\beta_{10} \text { Exercise } \\
& +\beta_{11} \text { Daily_activity }+\beta_{12} \text { Walk_fast }+\beta_{13} \text { Smoke }+\beta_{14} \text { Alcofol_freq } \\
& +\beta_{15} \text { Alcohol_amount }+\beta_{16} \text { Sleep }+\beta_{17} \text { Trend }+\beta_{18} \text { Wage }+u_{i} .
\end{aligned}
$$

The results of the estimation are given in Table 3. The variables affecting DBP were similar to those in the SBP models. The only difference was that estimates of Exercise became significant at the 5\% and 1\% levels in Models 2B and 2C, respectively.

\section{Discussion}

WHO [1] stated that "Globally, the overall prevalence of raised blood pressure in adults aged 25 and over was around $40 \%$ in 2008." This number became $22.3 \%$ in 2014 [30]. Although the ages and years were slightly different, there exists an enormous difference between these two numbers despite the fact that they were reported by the same very influential organization. Our result is close to the second result obtained by WHO; this fact suggests that the WHO findings [1] should be reexamined and revised to avoid unnecessary confusion.

Age and gender are very important variables affecting both SBP and DBP. There exists a large difference between males and females; which raises the question of whether the same BP criterion should be used for hypertension regardless of gender. As for age, as individuals grew 10 years older, their average SBP increased as much as $5 \mathrm{mmHg}$. BP and the risks of hypertension have been studied using a cohort study [12] [24]. A 10-year interval was used to define the age cohorts; however, the results of this study suggest that the 10 year interval might be too large, the distribution within cohorts should not be ignored, and the age cohorts should be revised to get more precise evaluations. 
Table 3. Results of estimation: DBP equations.

\begin{tabular}{|c|c|c|c|c|c|c|c|c|c|}
\hline \multirow[b]{2}{*}{ Variable } & \multicolumn{3}{|c|}{ Model 2A } & \multicolumn{3}{|c|}{ Model 2B } & \multicolumn{3}{|c|}{ Model 2C } \\
\hline & Estimate & S. E. & $t$-value & Estimate & S. E. & $t$-value & Estimate & S. E. & $t$-value \\
\hline Constant & 75.484 & 0.254 & 296.668 & 47.608 & 0.376 & 126.509 & 35.234 & 1.244 & 28.325 \\
\hline Age & 0.202 & 0.005 & $43.298^{*}$ & 0.199 & 0.005 & $38.856^{*}$ & 0.186 & 0.006 & $31.703^{*}$ \\
\hline Female & -6.516 & 0.080 & $-80.952^{*}$ & -3.488 & 0.096 & $-36.192^{\star}$ & -2.133 & 0.155 & $-13.734^{\star}$ \\
\hline Hight & & & & 0.093 & 0.066 & 1.402 & 7.223 & 0.657 & $10.996^{*}$ \\
\hline BMI & & & & 0.763 & 0.009 & $81.964^{\star}$ & 0.839 & 0.010 & $80.493^{*}$ \\
\hline Anamnesis & & & & 0.540 & 0.071 & $7.575^{\star}$ & 0.509 & 0.076 & $6.704^{*}$ \\
\hline Eat_fast & & & & 0.219 & 0.078 & $2.823^{*}$ & 0.156 & 0.082 & 1.908 \\
\hline Late_Supper & & & & 0.031 & 0.076 & 0.414 & -0.036 & 0.078 & -0.465 \\
\hline After_Supper & & & & -0.761 & 0.105 & $-7.273^{*}$ & -0.745 & 0.114 & $-6.528^{*}$ \\
\hline No_Breakfas & & & & 0.671 & 0.086 & $7.852^{*}$ & 0.665 & 0.087 & $7.619^{*}$ \\
\hline Exercise & & & & -0.215 & 0.096 & $-2.243^{+}$ & -0.290 & 0.103 & $-2.821^{*}$ \\
\hline Daily_activity & & & & -0.348 & 0.083 & $-4.191^{*}$ & -0.357 & 0.091 & $-3.923^{*}$ \\
\hline Walk_fast & & & & -0.002 & 0.074 & -0.023 & -0.026 & 0.079 & -0.335 \\
\hline Smoke & & & & -0.930 & 0.077 & $-12.096^{*}$ & -1.023 & 0.078 & $-13.079^{*}$ \\
\hline Alcofol_freq & & & & 1.218 & 0.064 & $18.928^{*}$ & 1.324 & 0.067 & $19.897^{*}$ \\
\hline $\begin{array}{c}\text { Alco- } \\
\text { hol_amount }\end{array}$ & & & & 0.701 & 0.048 & $14.728^{\star}$ & 0.724 & 0.049 & $14.850^{*}$ \\
\hline Sleep & & & & 0.649 & 0.073 & $8.838^{*}$ & 0.678 & 0.078 & $8.706^{*}$ \\
\hline Trend & & & & -0.059 & 0.041 & -1.426 & -0.042 & 0.045 & -0.949 \\
\hline Wage & & & & & & & -0.026 & 0.003 & $-8.560^{*}$ \\
\hline $\mathrm{R} 2$ & & 0.0692 & & & 0.1501 & & & 0.1331 & \\
\hline \multirow[t]{2}{*}{$\begin{array}{c}\text { No. of } \\
\text { mesurements }\end{array}$} & & 113,967 & & & 95,364 & & & 82,735 & \\
\hline & & 11.307 & & & 10.755 & & & 10.643 & \\
\hline
\end{tabular}

SE: Standard Error. ${ }^{+}$Significant at the $5 \%$ level. ${ }^{*}$ Significant at the $1 \%$ level.

The variables affecting BP other than the basic characteristics of individuals are similar to those in previous studies. Obesity increases BP, and a one point reduction of BMI reduces SBP and DBP by $1.1-1.3$ and $0.76-0.84 \mathrm{mmHg}$, respectively. Therefore, weight reduction is an effective method of controlling BP. Anamnesis increases BP. Individuals with risk factors are classified in the veryhigh-risk group if their hypertension is grade 3 [17]. Hence it is important for anamnesis to be cured in these individuals. Concerning eating habits, eating a proper breakfast reduces BP. Daily physical activity (even light activity) is another important factor for controlling BP. The results of this study suggest that smoking reduces $\mathrm{BP}$, although the other bad effects of smoking were not evaluated in this study. Drinking alcohol (both the frequency and amount per day) increases BP. Comparing to an individual who does not drink, the SBP and DBP of a heavy drinker (who drinks $540 \mathrm{ml}$ or more of sake wine every day) are more 
than $5.0 \mathrm{mmHg}$ higher on average. The effect of drinking is much larger than the effects of other factors. Sleeping well increases BP. Although this result is unexpected, the reason for it is unknown. The time trend is negative, but this result is not significant. Three years might be too short a span over which to measure the time trend. Both SBP and DBP decrease as wages increase. This suggests that higher social and economic status improves BP.

\section{Conclusions}

In this paper, we first evaluated the distribution of BP using 113,979 BP measurements in 48,022 individuals collected by the health insurance society of one large corporation in Japan. Such a dataset has not been used before in research such as this. The means of SBP and DBP were 125.4 and $77.6 \mathrm{mmHg}$, with SD of 16.5 and $11.7 \mathrm{mmHg}$, respectively. Under the $140 / 90$ criterion, $21.6 \%$ measurements had hypertension. According to the WHO-ISH criterion, $16.4 \%, 4.2 \%$ me and $0.96 \%$ were classified as grades 1,2 and 3, respectively. The factors affecting $\mathrm{BP}$ were then evaluated using a regression analysis. The factors affecting BP were age, gender, some eating habits, daily activities, smoking, drinking alcohol, sleeping, and wages. Age is a very important factor, and it is possible that the age cohorts in previous studies should be revised. Among the factors that individuals can control, the influence of drinking alcohol is very large. Compared to an individual who does not drink, the SBP and DBP of a heavy drinker are more than $5.0 \mathrm{mmHg}$ higher on average.

The dataset used in this study was obtained from just one health insurance society, and a sample selection bias might exist. We are now negotiating various health insurance societies to provide us their data. This study is the first step, and it will be possible for us to use health and medical datasets for a huge number of normal individuals, much bigger than any datasets ever used before. Companies are responsible for the health conditions of their employees, and they should encourage the high risk employees to control their BP. For the purpose of helping employees, other risk factors should be evaluated. The cost-benefit analysis is also necessary for effective use of medical resources. The family history is another interesting factor to be analyzed. These are subjects to be studied in future.

\section{Acknowledgements}

This study was approved by the Institutional Review Boards of the University of Tokyo (number: KE16-30). The authors would like to thank the health insurance society providing us the data for their sincere cooperation. We would also like to thank an anonymous referee for his/her helpful comments and suggestions.

\section{References}

[1] World Health Organization (2016) Raised Blood Pressure. http://www.who.int/gho/ncd/risk_factors/blood_pressure_prevalence_text/en/

[2] Blood Pressure Association, UK (2008) Blood Pressure Chart for Adults. 
http://www.bloodpressureuk.org/BloodPressureandyou/Thebasics/Bloodpressurech art

[3] Wohlfahrt, P., Cifková, R., Movsisyan, N., et al. (2016) Threshold for Diagnosing Hypertension by Automated Office Blood Pressure Using Random Population. Journal of Hypertension, 2180-2186. https://doi.org/10.1097/HJH.0000000000001076

[4] Omiboni, S., Aristizabal, D., De la Sierra, A., et al. (2016) Hypertension Types Defined by Clinic and Ambulatory Blood Pressure in 14142 Patients Referred to Hypertension Clinics Worldwide. Data from ARTEMIS Study. Journal of Hypertension, 34, 2187-2198. https://doi.org/10.1097/HJH.0000000000001074

[5] AACN Practice Alert (2016) Obtaining Accurate Noninvasive Blood Pressure Measurements in Adults. Critical Care Nurse, 36, e12-e16.

https://doi.org/10.4037/ccn2016590

[6] Keyarney, P.M., Whelton, M., Reynolds, K., et al. (2005) Global Burden of Hypertension: Analysis of Worldwide Data. Lancet, 365, 21-223.

[7] GBD 2013 Risk Factors Collaborates (2015) Global, Regional, and National Risk Assessment of 79 Behavioural, Environmental and Occupational, and Metabolic risks or Clusters of Risks in 188 Countries, 1990-2013: A Systematic Analysis for Global Burden of Disease Study 2013. Lancet, 386, 2287-2323.

https://doi.org/10.1016/S0140-6736(15)00128-2

[8] Gupta, R., Sharma, A.K. and Gupta, V.P. (2003) Increased Variance in Blood Pressure and Changing Hypertension Prevalence in an Indian Population. Journal of Human Hypertension, 17, 535-540. https://doi.org/10.1038/sj.jhh.1001588

[9] Alleyne, D. (2010) The Impact of User Fees on Health Costs and Health Burdens in Jamaica: The Cases of Diabetes and Hypertension. Social and Economic Studies, 59, 91-121.

[10] Ibrahim, M.M. and Damasceno, A. (2012) Hypertension in Developing Countries. Lancet, 380, 611-619. https://doi.org/10.1016/S0140-6736(12)60861-7

[11] Wachtell, K. and Okin, P.M. (2016) An Age-Old Test in Old Age: ECG Left Ventricular Hyperophy and Cardiovascular Outcomes in the Elderly. Journal of Hypertension, 34, 2145-2146. https://doi.org/10.1097/HJH.0000000000001107

[12] Chobanian, A.V., Bakris, G.L., Black, H.B., et al. (2003) Seventh Report of the Joint National Committee on Prevention, Detection, Evaluation, and Treatment of High Blood Pressure. Hypertension, 42, 1206-1252. https://doi.org/10.1161/01.HYP.0000107251.49515.c2

[13] National Heart, Lung, and Blood Institute and US Department of Health and Human Services (2004) National High Blood Pressure Education Program: Seventh Report of the Joint National Committee on Prevention, Detection, Evaluation, and Treatment of High Blood Pressure (Complete Report). https://www.nhlbi.nih.gov/files/docs/guidelines/jnc7full.pdf

[14] National Heart, Lung and Blood Institute and US Department of Health and Human Services (2015) Description of High Blood Pressure. https://www.nhlbi.nih.gov/health/health-topics/topics/hbp

[15] Vasan, S.R., Larson, M.G., Leip, E.P., et al. (2001) Impact of High-Normal Blood Pressure on the Risk of Cardiovascular Disease. New England Journal of Medicine, 345, 1291-1297. https://doi.org/10.1056/NEJMoa003417

[16] Prospective Studies Collaboration (2002) Age-Specific Relevance of Usual Blood Pressure to Vascular Mortality: A Meta-Analysis of Individual Data for One Million Adults in 61 Prospective Studies. Lancet, 360, 1903-1913. 
https://doi.org/10.1016/S0140-6736(02)11911-8

[17] Guidelines Subcommittee (1990) 1999 World Health Organization-International Society of Hypertension Guidelines for Management of Hypertension. Journal of Hypertension, 17, 151-183.

[18] Ministry of Health, Welfare, and Labor (2016) Heisei 26 nendo kokumin iryouhi no gayou [Summary of National Medical Expenditures]. (In Japanese)

[19] Codliffe, S. and Link, C.R. (2014) Racial Differences in the Effects of Hypertension and Obesity on Health Expenditures by Diabetes in the US. Applied Economics Letters, 21, 280-283. https://doi.org/10.1080/13504851.2013.856990

[20] Blanchflower, D.G. and Oswald, A.J. (2008) Hypertension and Happiness across Nations. Journal of Health Economics, 27, 218-233. https://doi.org/10.1016/j.jhealeco.2007.06.002

[21] Mojon-Azzi, S. and Sousa-Pazo, A. (2011) Hypertension and Life Satisfaction: An Analysis Using Data from the Survey of Health, Aging and Retirement in Europe. Applied Economics Letters, 18, 183-187. https://doi.org/10.1080/13504850903508291

[22] Joffres, M.R., Mamet, P., MacLean, D.R., et al. (2001) Distribution of Blood Pressure and Hypertension in Canada and the United States. American Journal of Hypertension, 14, 1099-1105. https://doi.org/10.1016/S0895-7061(01)02211-7

[23] Rose, G. (2001) Sick Individuals and Sick Populations. International Journal of Epidemiology, 30, 427-432. https://doi.org/10.1093/ije/30.3.427

[24] Gorman, B.K. and Porter, J.R. (2011) Social Networks and Support, Gender, and Radical/Ethic Disparities in Hypertension among Older Adults. Population Research \& Policy Review, 20, 885-911. https://doi.org/10.1007/s11113-011-9215-4

[25] Department of Public Health, Shiga University of Medical Sciences (2016) NIPPON DATA 2010. (In Japanese)

https://hs-web.shiga-med.ac.jp/Nippondata/NIPPONDATA2010/research/Data\%20 table/3_ketsuatsu.pdf

[26] Miura, K., Nagai, M. and Ohkubo, T. (2013) Epidemiology of Hypertension in Japan-Where Are We Now? Circulation Journal, 77, 2226-2231.

https://doi.org/10.1253/circj.CJ-13-0847

[27] Fujiyoshi, A., Ohkubo, T., Miura, K., et al. (2012) Blood Pressure Categories and Log-Term Risk of Cardiovascular Disease According to Age Group in Japanese Men and Women. Hypertension Research, 35, 947-953.

https://doi.org/10.1038/hr.2012.87

[28] Japanese Law Translation (2009) Industrial Safety and Health Act. http://www.japaneselawtranslation.go.jp/law/detail/?id=1926\&vm=\&re

[29] National Federation of Health Insurance Societies (2016) Kenporen ni tsuite. (In Japanese) http://www.kenporen.com/outline/

[30] World Health Organization (2015) Raised Blood Pressure (SBP $\geq 140$ or DBP $\geq 90$ ) Crude Data by WHO Region. http://apps.who.int/gho/data/view.main.2540?lang=en

[31] Ebrahim, S. and Smith, G.D. (1998) Lowering Blood Pressure: A Systematic Review of Sustained Effects of Non-Pharmacological Interventions. Journal of Public Health Medicine, 20, 441-448.

https://doi.org/10.1093/oxfordjournals.pubmed.a024800

[32] Leitter, L.A., Abbott, D. and Campbell, N.R.C. (1999) Recommendations on Obesity and Weight Loss. Canadian Medical Association Journal, 160, S7-S12.

[33] Xin, X., He, J., Frontini, M.G., Ogden, L.G., Motsamai, O.I. and Whelton, P.K. 
(2001) Effects of Alcohol Reduction on Blood Pressure: A Meta-Analysis of Randomized Controlled Trails. Hypertension, 38, 1112-1117.

https://doi.org/10.1161/hy1101.093424

[34] Stevens, V.J., Obarzanek, E., Cook, N.R., et al. (2001) Long-Term Weight Loss and Changes in Blood Pressure: Results of the Trials of Hypertension Prevention, Phase II. Annals of Medicine, 134, 1-11. https://doi.org/10.7326/0003-4819-134-1-200101020-00007

[35] Powdthavee, N. (2010) Does Education Reduce the Risk of Hypertension? Estimating the Biomarker Effect of Compulsory Schooling in England. Journal of Human Capital, 4, 173-202. https://doi.org/10.1086/657020

[36] Gerber, M., Endes, K., Herrmann, C., et al. (2016) Does Physical Fitness Buffer the Relationship between Psychosocial Stress, Retinal Vessel Diameters, and Blood Pressure among Primary Schoolchildren? BioMed Research International, 2016, Article ID: 6340431. https://doi.org/10.1155/2016/6340431

Submit or recommend next manuscript to SCIRP and we will provide best service for you:

Accepting pre-submission inquiries through Email, Facebook, LinkedIn, Twitter, etc. A wide selection of journals (inclusive of 9 subjects, more than 200 journals)

Providing 24-hour high-quality service

User-friendly online submission system

Fair and swift peer-review system

Efficient typesetting and proofreading procedure

Display of the result of downloads and visits, as well as the number of cited articles Maximum dissemination of your research work

Submit your manuscript at: http://papersubmission.scirp.org/

Or contact health@scirp.org 